\title{
Analysis on Driving Effect of the Urbanization Development Speed on Water Resources Conflict
}

\author{
Xiaoyuan Wu, ${ }^{1}$ Changxin Xu, ${ }^{1}$ and Qinghua Pang ${ }^{2}$ \\ ${ }^{1}$ Business School, Hohai University, Nanjing 211100, China \\ ${ }^{2}$ School of Business Administration, Hohai University, Changzhou 213022, China \\ Correspondence should be addressed to Qinghua Pang; pangqh77@126.com
}

Received 20 September 2016; Revised 28 November 2016; Accepted 12 December 2016; Published 24 January 2017

Academic Editor: Manuel Herrera

Copyright (C) 2017 Xiaoyuan Wu et al. This is an open access article distributed under the Creative Commons Attribution License, which permits unrestricted use, distribution, and reproduction in any medium, provided the original work is properly cited.

\begin{abstract}
This paper aims to research the driving effect of the urbanization development speed on water resources conflict by building the risk stress coupling analysis model of urbanization development speed and water conflict. Firstly, we use the nonlinear fuzzy comprehensive adjustment (FCA) measure model based on entropy weight method to determine the level of urbanization and water resources conflict risk, then construct the coupling coordination degree function of urbanization speed and water conflict risk pressure, and calculate the coupling coordination degree. Secondly, we determine the level of water resources conflict according to the coupling coordination degree to obtain the trigger threshold value of water resources conflict and analyze the coupling results. Lastly, we start the instance analysis with Beijing City, Tianjin City, and Hebei Province region in Haihe river basin of China, as an example, by analyzing the influence of the urbanization speed on water resource conflict and by obtaining the threshold value of water resources conflict caused by the effect of water consumption of gross domestic product (GDP) per 10 thousand Yuan and annual per capita domestic water consumption on the urbanization development speed, expressed in interval number.
\end{abstract}

\section{Introduction}

The researches on the conflict relationship between urbanization development and water conflict have made some process, which can be divided into three aspects. (1) Research on The Interact Relationship between Urbanization and Water Conflict. Majumder [1] explained how does climate change happen and what influence does it make, and also he creatively put forward the notion of climate models, Global Climate Model (GCM) and Regional Climate Model (RCM). Some of Chinese scholars believe that a complicated effect relationship exists objectively between urbanization development speed and water resource conflict [2]. They hold the opinion that acceleration of urbanization development speed brings great pressure to ecological environment [3], and urbanization which leads to water demand increase and water resource shortage has become one of important factors for water resource conflict [4]. (2) Research on Coupling Coordination Method. In 1999, Liao [5] puts forward harmonious development model of economy and environment of coordination degree between two systems that are mutually coupled. After that, many researches regarding coordination degree between economy and environment are developed within country, of which research regarding coupling coordination degree between urbanization and ecological environment gains many achievements, such as that by Liu et al. who put forward a coordinative criteria model which takes urbanization and ecological environment into account [6]. Wang et al. [7] make use of coupling coordination model to analyze coordination evolution tendency of Tianshui urbanization and ecological environment. Ma et al. [8] perform quantitative analysis to coupling coordination of Gansu urbanization and ecological environment. (3) Research on Related Applications. Bao and Fang [9] took arid regions of northwest China as research objects and researched on water resources constraint force in the process of urbanization in water deficient regions and pointed out that water resources constraint force (WRCF) should be applied when analyzing water crisis on rapid urbanization especially in arid and semiarid areas all over the world. Furey and Lutyens [10] took Ashford region as an example to illustrate how to overcome the conflict between water infrastructure and environmental quality and thought 
that the latest problems happening with water environment set up the dominating constraints to growth which could come out from the proposed development and scientific water management strategies for the purpose of adapting to Ashford's expansion. Apart from it, this paper reviews the integration methodology which was developed and discussed from the experience.

After viewing extensive literature searched in the database, the current researches on urbanization development and water conflict are found to have some deficiency which can be divided into three aspects. The first aspect is that research range of these methods is restricted to layer of region, and research regarding basin water resource conflict is few. The second aspect is that achievements of research to impact mechanism of water resource conflict from perspective of urbanization development speed are not so many. The last aspect is that there is not any research method concerning the water resource conflict risk pressure and risk level assessment.

\section{Mutual Coupling Relationship between Urbanization Development Speed and Water Resource Conflict Risk Pressure}

Coupling effect of urbanization development speed and water resource conflict risk pressure is mainly embodied in two aspects: the first aspect is that urbanization development speed directly affects water resource conflict risk pressure. Water resource conflict risk pressure is generally decided by factors, such as water demand, available water supply, discharge of waste water, effect degree on ecological environment, and whether basin water resource management system is improved. Fast or slow degree of urbanization directly affects water volume access degree of each region within basin, strength of pollution discharge demand, and effect degree on ecological environment. Once water volume, water quality, and ecological environment exceed bearing range, water resource conflict may be caused. The second aspect is that water resource conflict risk pressure restricts urbanization development speed [11-15]. Urbanization development speed can be measured by analyzing urbanization levels at different stages. Urbanization level is generally quantified from three aspects, that is, population urbanization level, economy urbanization level, and social space urbanization level. Once water resource conflict risk pressure changes, it will affect urbanization level from aspect of water volume, water quality and ecological environment, and so forth, thus affecting urbanization development speed. See Figure 1 for specific mutual coupling relationship between urbanization development speed and water resource conflict risk pressure.

By constructing coupling analysis model of urbanization development speed and water resource conflict risk pressure, we can quantitatively measure coupling relationship and coordination degree of two systems and analyze coupling change of different urbanization levels and water resource conflict risk levels of some regions or cities. Then impact mechanism of urbanization development speed to water resource conflict will be analyzed.

\section{Determination of Urbanization Level and Water Resources Conflict Risk Level}

3.1. The Reason Why Urbanization Level and Water Resources Conflict Risk Level Should Be Determined. To express the coupling relationship between urbanization and water conflict, two key elements as urbanization development speed and water resources conflict risk pressure can be determined by measuring urbanization level and water resources conflict risk level.

(1) Use Urbanization Level in Different Stage to Determine the Urbanization Development Speed. Urbanization development speed is the physical quantity for showing the speed level and direction of urbanization development. Urbanization development speed is vector. Urbanization development speed of a city or a region from year $t$ to year $(t+i)(i \geq 1)$ is characterized in the paper:

$$
\tilde{f}(t+i)=\frac{|f(t+i)-f(t)|}{i \cdot f(t)},
$$

where $f(t)$ is the measure value of urbanization development speed of a city or a region in year $t$. In particular, when $i=1$, urbanization development speed of $\widetilde{f}(t+1)=\mid f(t+1)-$ $f(t) \mid / f(t)$ of a city or a region in year $(t+i)$ can be obtained.

(2) Use Water Resources Conflict Risk Level to Determine Water Resources Conflict Risk Pressure. Water resources conflict risk pressure is the physical quantity for showing the speed level and direction of generation for water resources conflict risk. Water resources conflict risk pressure is vector with size and direction. Water resources conflict risk pressure of a city or a region from the year $t$ to year $(t+i)(i \geq 1)$ is characterized in the paper:

$$
\widetilde{g}(t+i)=\frac{|g(t+i)-g(t)|}{i \cdot g(t)},
$$

where $g(t)$ is the measure value of water resources conflict risk level in year $t$. In particular, when $i=1$, water resources conflict risk pressure of $\widetilde{g}(t+1)=|g(t+1)-g(t)| / g(t)$ of a city or a region in year $(t+1)$ can be obtained.

\subsection{Method to Determine the Urbanization Level and Water Resources Conflict Risk Level. Factors affecting measurement of urbanization level and water resource conflict risk level are various with complex layers. Information has uncertainty. Preprocessing has to be performed to index if scientific measurement has to be performed to it. Fuzzy comprehensive adjustment (FCA) measure model can embody uncertain information with quantitative method, and judgment grade of judgment object and degree where it is attached to each grade can be gained through comprehensive judgment matrix gained through blurring operation [16]. Therefore, FCA model can be adopted to measure basin water resource conflict risk level. But FCA model is still a linear weighting measurement method, and it cannot reflect prominent influ- ence owned by some measurement indexes [17]. Considering}




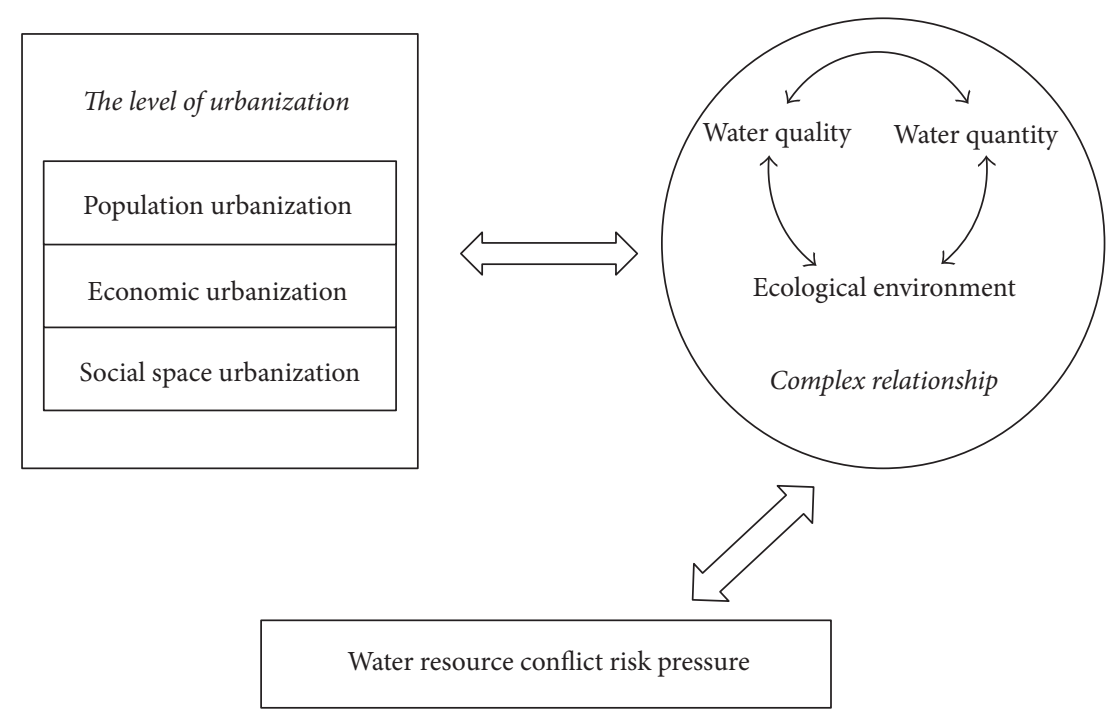

FIGURE 1: Mutual coupling relationship figure of urbanization development speed and water resource conflict risk pressure.

that nonlinear measurement model is more suitable for actual circumstances $[18,19]$, this paper adopts nonlinear FCA model and combined with entropy weight method to perform measurement to urbanization level and water resource conflict risk level.

The process of building the nonlinear FCA measuring model based on entropy weight method is as follows.

(1) The Indexes Are Processed on a Dimensionless Basis to Determine the Matrix. Assuming that the measuring factor set consisting of measuring indexes is $U=\left\{U_{1}, U_{2}, \ldots, U_{s}\right\}$, the actual value of measuring indexes is $\left\{u_{1}, u_{2}, \ldots, u_{s}\right\}$. The remark grade domain of discourse $V=\left\{V_{1}, V_{2}, V_{3}\right\}$ is decision $l$ that describes the status of each factor, that is, the measuring grade. The critical value of grades corresponding to measuring factor $U_{i}$ is $\left\{0, v_{i 1}, v_{i 2}, 1\right\}$. The index grading values are included in Table 1.

$r_{i j}$ denotes the membership degree of measure factor $U_{i}$ to grade $V_{j}$. Calculation of the value can be done with the following membership function formula according to the actual value and the grading indexes of measuring factors. For any measuring factor $U_{i}$, if the corresponding actual value is $u_{i}, i=1,2, \ldots, s$, then

$$
r_{i j}\left(u_{i}\right)= \begin{cases}0.5\left(1-\frac{k_{i 1}-u_{i}}{k_{i 2}-u_{i}}\right), & u_{i}<k_{i 1} ; \\ 0.5\left(1+\frac{u_{i}-k_{i 1}}{k_{i 2}-k_{i 1}}\right), & k_{i 1} \leq u_{i}<k_{i 2} ; \\ 0.5\left(1+\frac{k_{i 3}-u_{i}}{k_{i 3}-k_{i 2}}\right), & k_{i 2} \leq u_{i}<k_{i 3} ; \\ 0.5\left(1-\frac{u_{i}-k_{i 3}}{u_{i}-k_{i 2}}\right), & k_{i 3} \leq u_{i},\end{cases}
$$

where $k_{i 1}$ is the critical value of grades $V_{1}$ and $V_{2}$ that correspond to measuring factor $U_{i}$; that is, $k_{i 1}=v_{i 1} ; k_{i 2}$ is the interval midpoint value of grade $V_{2}$ that corresponds to measuring factor $U_{i}$; that is, $k_{i 2}=\left(v_{i 1}+v_{i 2}\right) / 2 ; k_{i 3}$ is the critical value of grades $V_{2}$ and $V_{3}$ that correspond to
TABLE 1: Measuring index grade values of rating target.

\begin{tabular}{lcccc}
\hline \multirow{2}{*}{ Measuring grade } & \multicolumn{5}{c}{ Measuring index grade values } \\
& $U_{1}$ & $U_{2}$ & $\ldots$ & $U_{s}$ \\
\hline$V_{1}$ & $0<v_{11}$ & $0<v_{21}$ & $\ldots$ & $0<v_{s 1}$ \\
$V_{2}$ & $v_{11} \sim v_{12}$ & $v_{21} \sim v_{22}$ & $\ldots$ & $v_{s 1} \sim v_{s 2}$ \\
$V_{3}$ & $1>v_{12}$ & $1>v_{22}$ & $\ldots$ & $1>v_{s 2}$ \\
\hline
\end{tabular}

measuring factor $U_{i}$; that is, $k_{i 3}=v_{i 2}$. With calculations, the evaluation matrix of the measuring target is $R=\left(r_{i j}\right)_{s \times 3}$.

(2) Determination of Measuring Index Weight Based on Entropy Weight Method. The entropy weight of measuring indexes $W=\left(w_{1}, w_{2}, \ldots, w_{s}\right)$ is determined with entropy weight method. Entropy weight $w_{j}$ represents the amount of information of an index. A bigger entropy weight means that the index plays a bigger role in comprehensive decisionmaking, which directly and effectively reflects the degree of difference among indexes.

(3) Nonlinear Fuzzy Comprehensive Evaluation. The fuzzy matrix composition operator is defined. Measuring indexes are reclassified according to the correlation between measuring indexes $U_{1} \sim U_{s}$ and the measuring target and based on evaluations by experts. It is assumed that the index prominent influencing degree coefficient vector is $\left(\Lambda=\left(\lambda_{1}, \lambda_{2}, \ldots, \lambda_{n}\right)\right.$, $\lambda_{i} \geq 1$, where the higher prominent influencing degree of index $U_{i}$ on the measuring result there is, the bigger $\lambda_{i}$ there will be. When index $U_{i}$ has no prominent influence, $\lambda_{i}$ will be 1. For simplicity, $\lambda_{i}$ may be an integer equal to or greater than 1 .

Assuming $\lambda=\max \left\{\lambda_{1}, \lambda_{2}, \ldots, \lambda_{s}\right\}$, it is defined that the composition operator of nonlinear fuzzy matrix is $f_{j}\left(w_{1}, w_{2}, \ldots, w_{s} ; y_{1}, y_{2}, \ldots, y_{s} ; \Lambda\right)=\left(w_{1} r_{1 j}{ }^{\lambda_{1}}+w_{2} r_{2 j}{ }^{\lambda_{2}}+\right.$ $\left.\cdots+w_{s} r_{s j}{ }^{\lambda_{n}}\right)^{1 / \lambda}$, where $w_{j}>0$ and $\sum_{j=1}^{s} w_{j}=1 ; r_{j}=$ $\left(r_{1 j}, r_{2 j}, \ldots, r_{s j}\right), 1 \leq j \leq s$. The membership matrix of 
measuring objects must be appropriately transformed upon application of the operation to fuzzy matrix composition as fuzzy comprehensive measuring generally has $r_{i j} \in[0,1]$ as the membership. The membership value is turned to be a number that is greater than 1 . It can be obtained that $r_{i j}^{\prime}=a^{r_{i j}}$ $(a>1)$ and $R=\left(a^{r_{i j}}\right)_{s \times 3}$.

Finally, the fuzzy comprehensive measuring model is obtained to be

$$
\begin{aligned}
B & =W \cdot R=\left(w_{1}, w_{2}, \ldots, w_{s}\right)\left[\begin{array}{llll}
a^{r_{11}} & a^{r_{21}} & \cdots & a^{r_{s 1}} \\
a^{r_{12}} & a^{r_{22}} & \ldots & a^{r_{s 2}} \\
a^{r_{13}} & a^{r_{23}} & \cdots & a^{r_{s 3}}
\end{array}\right]^{T} \\
& =\left(b_{1}, b_{2}, b_{3}\right),
\end{aligned}
$$

where $r_{i j}$ denotes the membership of measuring factor $U_{i}$ in grade $V_{j} . w_{j}$ is the index weight. The maximum membership value, also known as fuzzy comprehensive measured value, is obtained with the maximum membership method. The measuring grade into which the measuring target falls is determined.

\subsection{Determination of Urbanization Level and Water Resource Conflict Risk Level}

(1) Determination of Urbanization Level. With the help of the measuring index system of urbanization level, the fuzzy comprehensive measured value $f(t)$ of urbanization level of a city or a region in year $t$ can be obtained by using the nonlinear FCA measuring model based on entropy weight method, where $f$ is the nonlinear fuzzy function regarding an urbanization level measuring index.

(2) Determination of Water Resources Conflict Risk Level. With the help of the measuring index system of water resources conflict risk level, the fuzzy comprehensive measured value $g(t)$ of water resources conflict risk level in year $t$ can be obtained by using the nonlinear FCA measuring model based on entropy weight method, where $g$ is the nonlinear fuzzy function regarding a measuring index of water resources conflict risk level.

\section{Coupling Coordination Judgment between Urbanization Development Speed and Water Resource Conflict}

4.1. Construction of Coupling Coordination Development Degree Function. On the basis of research for coordination development model of economy and environment put forward by $\mathrm{Hu}$ et al. [19], with reference to its coupling function construction idea of quantifying the coordination degree between the mutually coupled two systems, construct coupling coordination function between urbanization development speed and water resources conflict risk pressures. For order parameters $\widetilde{f}(t)$ and $\tilde{g}(t)$ of urbanization development speed and water resources conflict risk pressure in a city or a region in year $t$, relative deviation coefficient between the two shall be defined as $C_{v}=4\left[1-(4 \tilde{f}(t) \tilde{g}(t)) /(\tilde{f}(t)+\widetilde{g}(t))^{2}\right]$; the smaller the deviation coefficient $C_{v}$ is, the better the coordination degree between the two is. Because $\widetilde{f}(t) \geq 0$ and $\widetilde{g}(t) \geq 0$, the condition of minimum $C_{v}$ is $(4 \tilde{f}(t) \widetilde{g}(t)) /(\tilde{f}(t)+$ $\widetilde{g}(t))^{2} \rightarrow 1$.

Coordination degree between urbanization development speed and water resources conflict risk pressure can be expressed as $G(t)=\left[(4 \tilde{f}(t) \tilde{g}(t)) /(\tilde{f}(t)+\widetilde{g}(t))^{2}\right]^{\psi}$, where $\psi$ is accommodation coefficient, $\psi \geq 2$, and its value shall be determined according to the specific conditions. For coordination degree $G(t)$ between urbanization development speed and water resources conflict risk pressure, we can draw the following two conclusions: (1) As $\widetilde{f}(t) \geq 0$, $\widetilde{g}(t) \geq 0,0 \leq G(t) \leq 1$; (2) the smaller the deviation coefficient is, the closer to 1 the value of $G(t)$ is and the better the coordination degree between urbanization development speed and water resources conflict risk pressure is.

In order to further elaborate coupling coordination development relation between urbanization development speed and water resources conflict risk pressure, introduce comprehensive compatibility index variable $T(t)$, which reflects overall coordination effect or contribution between urbanization development speed and water resources conflict risk pressure. Based on the above analysis, coupling coordination development degree function can be defined as follows:

$$
\begin{aligned}
C(t) & =[G(t) T(t)]^{\tau}, \\
G(t) & =\left[\frac{4 \tilde{f}(t) \tilde{g}(t)}{(\tilde{f}(t)+\widetilde{g}(t))^{2}}\right]^{\psi}, \\
T(t) & =\tilde{f}(t)^{\varphi} \tilde{g}(t)^{\gamma},
\end{aligned}
$$

where $G(t)$ is the coordination degree between urbanization development speed and water resources conflict risk pressure, $T(t)$ is comprehensive compatibility index between urbanization development speed and water resources conflict risk pressure, $\tau$ is coordination development coefficient, $0 \leq \tau \leq$ $1, \psi$ is accommodation coefficient, $\tau \geq 2, \varphi$ and $\gamma$ are undetermined weight number, and $\varphi+\gamma=1$. Due to the fact that the urbanization development speed is equally important as the water resources conflict risk pressure in all regions within the basin, $\varphi=\gamma=0.5$.

4.2. Threshold Value of Water Resources Conflict Obtained Based on Coupling Coordination Degree. Based on coupling coordination degree $C(t)$ calculated according to urbanization development speed and water resources conflict risk pressure, determine the level of water resources conflict and obtain the threshold value triggering water resource conflict. The specific calculation and analysis process is as follows. As $0 \leq G(t) \leq 1,0 \leq \tilde{f}(t) \leq 1$ and $0 \leq \tilde{g}(t) \leq 1$, $0 \leq C(t) \leq 1$. The value of $C(t)$ is between 0 and 1 ; the bigger it is, the better the coordination degree is. Conversely, the smaller it is, the worse the coordination degree is. When $C(t)=1$, coupling coordination development level is the 
TABLE 2: Level and its distinguish criterion of coupling coordination development degree and water resources conflict.

\begin{tabular}{|c|c|c|c|c|}
\hline $\begin{array}{l}\text { Coupling coordination } \\
\text { type }\end{array}$ & $\begin{array}{l}\text { Discrimination } \\
\text { interval }\end{array}$ & $\begin{array}{l}\text { Coupling } \\
\text { coordination rank }\end{array}$ & $\begin{array}{l}\text { Water resources } \\
\text { conflict level }\end{array}$ & Relation feature \\
\hline \multirow{2}{*}{$\begin{array}{l}\text { Disordered } \\
\text { development type } \\
\text { (unacceptable range) }\end{array}$} & $0<C(t) \leq 0.1$ & $\begin{array}{c}\text { Severely } \\
\text { disordered }\end{array}$ & $\begin{array}{l}\text { Severe water } \\
\text { resources conflict }\end{array}$ & $\begin{array}{c}\text { Urbanization has great pressure on water } \\
\text { resources. }\end{array}$ \\
\hline & $0.1<C(t) \leq 0.3$ & Slightly disordered & $\begin{array}{l}\text { Slight water } \\
\text { resources conflict }\end{array}$ & $\begin{array}{l}\text { Urbanization has relatively great pressure } \\
\text { on water resources. }\end{array}$ \\
\hline Transition type & $0.3<C(t) \leq 0.5$ & Low coordination & $\begin{array}{l}\text { Micro water } \\
\text { resource conflict }\end{array}$ & $\begin{array}{l}\text { Urbanization has existent pressure on } \\
\text { water resources. }\end{array}$ \\
\hline \multirow{3}{*}{$\begin{array}{l}\text { Coordination } \\
\text { development type } \\
\text { (acceptable range) }\end{array}$} & $0.5<C(t) \leq 0.7$ & $\begin{array}{l}\text { Moderate } \\
\text { coordination }\end{array}$ & $\begin{array}{l}\text { No water resource } \\
\text { conflict }\end{array}$ & $\begin{array}{l}\text { Urbanization basically coordinates with } \\
\text { water resources. }\end{array}$ \\
\hline & $0.7<C(t) \leq 0.9$ & High coordination & $\begin{array}{l}\text { No water resource } \\
\text { conflict }\end{array}$ & $\begin{array}{c}\text { Urbanization and water resources } \\
\text { promote each other }\end{array}$ \\
\hline & $0.9<C(t) \leq 1$ & $\begin{array}{l}\text { Extreme } \\
\text { coordination }\end{array}$ & $\begin{array}{l}\text { No water resource } \\
\text { conflict }\end{array}$ & $\begin{array}{l}\text { Efficient and coordinated development } \\
\text { stage of urbanization and water resources }\end{array}$ \\
\hline
\end{tabular}

biggest. Benign resonance coupling is reached among systems or among the internal elements of the system. The system tends to new ordered structure with mutual promotion between urbanization development and development and utilization of water resources and efficient and coordination development. When $C(t)=0$, coupling coordination development level is very small thus resulting in disordered development of the system; the pressure of urbanization development speed on development and utilization of water resources is relatively big or water resources conflicts affect the urbanization process. Types and discrimination criteria, corresponding water resources conflict level, relation feature between urbanization and water resources conflict of the following coupling coordination development level are set in the paper, which is as shown in Table 2 for specific conditions.

If $0<C(t) \leq 0.1$ and $0.1<C(t) \leq 0.3$, namely, it is the coupling coordination type between urbanization development speed and water resources conflict risk pressure that belongs to disordered development type; coupling coordination levels, respectively, are severely disordered development coupling and slightly disordered development coupling. The pressure of urbanization on water resources will lead to the water resources conflict. The size of water resources conflict risk pressure is usually caused by the water quantity conflict, water quality conflict, and ecological environment conflict. At this time, we can combine the coupling coordination type with the actual conditions of research area and obtain threshold value causing water resources conflict.

If $0.3<C(t) \leq 0.5$, namely, it is that the coupling coordination type between urbanization development speed and water resources conflict risk pressure that belongs transition type; coupling coordination level is low coordination development coupling. The urbanization process has less pressure on water resources. At this time, we can combine the coupling coordination type with the actual conditions of region and obtain threshold value causing water resources conflict.
If $0.5<C(t) \leq 0.7,0.7<C(t) \leq 0.9$, and $0.9 \leq$ $C(t)<1$, coupling coordination type between urbanization development speed and water resources conflict risk pressure belongs to coordination development type; coupling coordination level is moderate coordination development coupling, high coordination development coupling, and extreme coordination development coupling. Urbanization can coordinate water resources, which means there is no water resources conflict problem.

\section{Application: Take Beijing City, Tianjin City, and Hebei Province in Haihe River Basin of China, for Example}

5.1. Data Collection and Processing. In this paper, Beijing City, Tianjin City, and Hebei Province in Haihe river basin of China are taken as researched regions and years from 2005 to 2010 are selected as analyzed time period since the urbanization process and water resources conflict in Beijing City, Tianjin City, and Hebei Province in Haihe river basin of China fluctuated on different extents in this period, which is beneficial to analysis on coupling influence relationship between them, where total numbers of water resources conflict in above-scale in Beijing City, Tianjin City, and Hebei Province in Haihe river basin of China are, respectively, $\{0,0,12,2,0,4\}$ from 2005 to 2010 . Measurement index system of urbanization level and water resources conflict risk level is established with reference to existing relevant research achievements [11-15, 20-22] and combination of connotation and characteristic of urbanization and water resources conflict. Basic data collected is showed in Tables 3 and 4 .

5.2. Calculation of Urbanization Level and Water Resources Conflict Risk Level. Weights of urbanization level measure index and water resources conflict risk level measure index are determined, respectively, based on entropy method, where 
TABLE 3: Measurement index parameter values of urbanization level in Beijing City, Tianjin City, and Hebei Province in Haihe river basin of China from 2005 to 2010.

\begin{tabular}{|c|c|c|c|c|c|c|}
\hline Year & 2005 & 2006 & 2007 & 2008 & 2009 & 2010 \\
\hline Number of urban population ( $10^{4}$ human $)$ & 1927.09 & 1976.60 & 2064.22 & 2206.94 & 2310.94 & 2454.98 \\
\hline Urbanization rate $(\%)$ & 52.66 & 53.23 & 54.18 & 54.99 & 55.94 & 56.75 \\
\hline The proportion of tertiary industry employment (\%) & 40.95 & 42.07 & 42.79 & 44.14 & 44.69 & 45.17 \\
\hline Per capita GDP (Yuan) & 26440.33 & 29895.83 & 34993.40 & 39890.18 & 42363.97 & 47667.38 \\
\hline Economic density $\left(10^{4}\right.$ Yuan $\left./ \mathrm{km}^{2}\right)$ & 1903.38 & 2218.85 & 2657.14 & 3082.79 & 3433.52 & 4043.05 \\
\hline The proportion of the secondary and the tertiary industry (\%) & 91.00 & 91.76 & 91.63 & 91.97 & 91.93 & 92.12 \\
\hline GDP density of the secondary and the tertiary industry $\left(10^{4}\right.$ Yuan $\left./ \mathrm{km}^{2}\right)$ & 1832.51 & 2144.71 & 2570.28 & 2996.44 & 3330.03 & 3924.84 \\
\hline Per capita industrial output (Yuan) & 9508.35 & 10688.88 & 12219.49 & 14089.47 & 14339.97 & 16444.83 \\
\hline Per capita disposable income of urban residents (Yuan) & 11959.03 & 13530.32 & 15180.71 & 17378.17 & 18952.67 & 20893.95 \\
\hline Per capita living area $\left(\mathrm{m}^{2} /\right.$ human $)$ & 21.72 & 22.17 & 27.53 & 27.13 & 27.61 & 27.39 \\
\hline Urban density (human $/ \mathrm{km}^{2}$ ) & 581.32 & 591.41 & 602.59 & 615.58 & 628.60 & 669.97 \\
\hline Per capita public green area $\left(\mathrm{m}^{2}\right)$ & 8.72 & 9.05 & 9.70 & 10.52 & 11.13 & 11.68 \\
\hline Per capita road pavement area $\left(\mathrm{m}^{2}\right)$ & 10.15 & 10.35 & 11.28 & 11.84 & 12.55 & 13.68 \\
\hline Number of buses per ten thousand people (pcs) & 9.84 & 10.93 & 11.01 & 11.25 & 11.88 & 11.83 \\
\hline
\end{tabular}

TABLE 4: Measurement index parameter values of water resource conflict risk level in Beijing City, Tianjin City, and Hebei Province in Haihe river basin of China from 2005 to 2010 .

\begin{tabular}{|c|c|c|c|c|c|c|}
\hline Year & 2005 & 2006 & 2007 & 2008 & 2009 & 2010 \\
\hline Volume of water $\left(10^{8} \mathrm{~m}^{3}\right)$ & 131.73 & 132.95 & 132.26 & 127.79 & 127.27 & 127.06 \\
\hline Water consumption of GDP per 10 thousands Yuan (tons) & 140.99 & 123.68 & 103.75 & 85.25 & 78.75 & 66.24 \\
\hline Annual per capita domestic water consumption (tons) & 204.89 & 205.83 & 202.64 & 196.06 & 193.19 & 189.16 \\
\hline Sewage treatment rate $(\%)$ & 56.73 & 65.86 & 68.33 & 77.28 & 82.75 & 88.23 \\
\hline Industrial wastewater discharge standards rate (\%) & 97.60 & 95.87 & 96.93 & 96.86 & 98.62 & 98.82 \\
\hline Environmental water $\left(10^{8} \mathrm{~m}^{3}\right)$ & 1.03 & 1.20 & 1.54 & 1.72 & 1.92 & 2.22 \\
\hline
\end{tabular}

$$
\begin{aligned}
& W=(0.0709,0.0706,0.0706,0.0722,0.0732,0.0706,0.0733,0.0722,0.0721,0.0710,0.0707,0.0711,0.0710,0.0707) \\
& \widetilde{W}=(0.0024,0.4343,0.0064,0.1383,0.0007,0.4179) .
\end{aligned}
$$

Urbanization level and water resources conflict level are determined based on nonlinear FCA. (1) Determine urbanization level. (1) Judge matrix calculation. Assuming that measure factor set constituted by various measure index of urbanization level is $U=\left\{U_{1}, U_{2}, \ldots, U_{14}\right\}$ and the actual value of various measure index in year $t$ are $\left\{u_{1}^{t}, u_{2}^{t}, \ldots, u_{14}^{t}\right\}$, comment grade discourse domain $V=\left\{V_{1}, V_{2}, V_{3}\right\}$ and $V_{1}, V_{2}, V_{3}$ represent lower, middle, and high urbanization level. Measure index grade values of urbanization levels in Beijing City,
Tianjin City, and Hebei Province in Haihe river basin of China are determined as shown in Table 5 with reference to relevant literature and experts' comprehensive evaluation.

Judgment matrix of urbanization levels from 2005 to 2010 in Beijing City, Tianjin City, and Hebei Province can be obtained as follows according to the actual values of various measure factors from 2005 to 2010 with contrast of grade indexes of various measure factors and by calculating membership function formula (1):

\footnotetext{
$R_{1}$

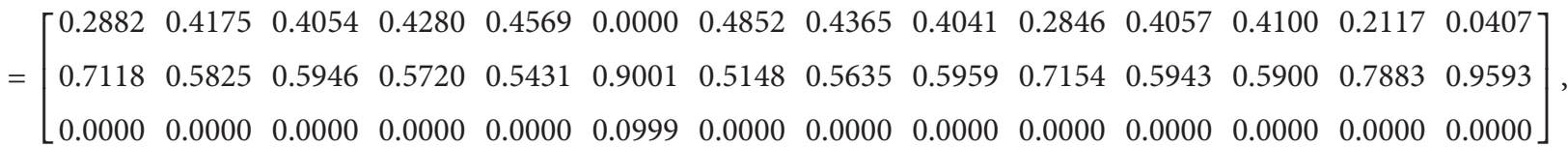




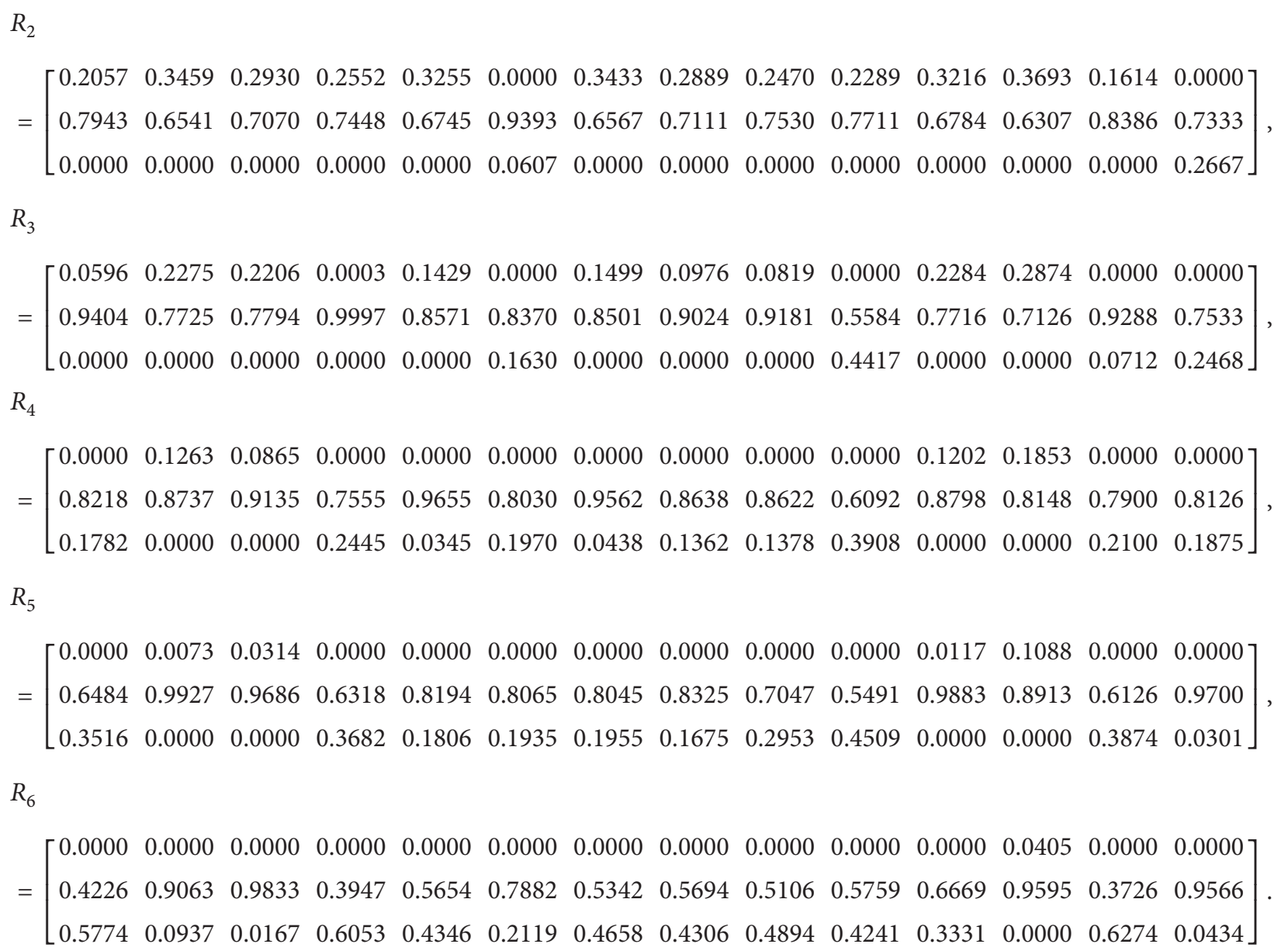

Calculate nonlinear fuzzy comprehensive level: urbanization levels in Beijing City, Tianjin City, and Hebei Province from 2005 to 2010 are determined as follows with combination of formula (2)

$$
\begin{aligned}
& B_{1}=W \cdot R_{1}=(0.3349,0.6580,0.0071), \\
& B_{2}=W \cdot R_{2}=(0.2424,0.7345,0.0231), \\
& B_{3}=W \cdot R_{3}=(0.1068,0.8278,0.0654), \\
& B_{4}=W \cdot R_{4}=(0.0367,0.8377,0.1256), \\
& B_{5}=W \cdot R_{5}=(0.0113,0.8010,0.1877), \\
& B_{6}=W \cdot R_{6}=(0.0029,0.6297,0.3228) .
\end{aligned}
$$

Calculate urbanization level: urbanization levels in Beijing City, Tianjin City, and Hebei Province from 2005 to 2010 can be obtained as follows according to maximum membership principle $f=(f(1), f(2), \ldots, f(6))=$ $(0.6580,0.7435,0.8278,0.8377,0.8010,0.6297)$.

Determine water resource conflict risk level: (1) judge matrix calculation. Assuming that measure factor set constituted by various measure index of water resource conflict risk level is $\widetilde{U}=\left\{\widetilde{U}_{1}, \widetilde{U}_{2}, \ldots, \widetilde{U}_{6}\right\}$ and the actual valued of various measure index in year $t$ are $\left\{\widetilde{u}_{1}^{t}, \widetilde{u}_{2}^{t}, \ldots, \widetilde{u}_{6}^{t}\right\}$, comment grade discourse domain $\widetilde{V}=\left\{\widetilde{V}_{1}, \widetilde{V}_{2}, \widetilde{V}_{3}\right\}$ and $\widetilde{V}_{1}, \widetilde{V}_{2}, \widetilde{V}_{3}$ represent lower, middle, and high water resource conflict risk level. Measure index grade values of water resource conflict risk levels in Beijing City, Tianjin City, and Hebei Province in Haihe river basin of China are determined as shown in Table 6 with reference to relevant literature and experts' comprehensive evaluation.

Judgment matrix of water resource conflict risk levels from 2005 to 2010 in Beijing City, Tianjin City, and Hebei Province can be obtained as follows according to the actual values of various measure factors from 2005 to 2010 with contrast of grade indexes of various measure factors and by calculating membership function formula (1):

$$
\begin{aligned}
& \widetilde{R}_{1} \\
& =\left[\begin{array}{lllllll}
0.0000 & 0.0000 & 0.0852 & 0.3229 & 0.0000 & 0.4763 \\
0.8275 & 0.6901 & 0.9148 & 0.6771 & 0.6008 & 0.5237 \\
0.1725 & 0.3099 & 0.0000 & 0.0000 & 0.3992 & 0.0000
\end{array}\right],
\end{aligned}
$$


TABle 5: Measure index grade values of urbanization levels in Beijing City, Tianjin City, and Hebei Province in Haihe river basin of China.

\begin{tabular}{|c|c|c|c|}
\hline Level grade & Low & Middle & High \\
\hline Number of urban population (in ten thousand) & $<1800$ & $1800 \sim 2400$ & $>2400$ \\
\hline Urbanization rate $(\%)$ & $<52$ & $52 \sim 60$ & $>60$ \\
\hline The proportion of tertiary industry employment (\%) & $<40$ & $40 \sim 50$ & $>50$ \\
\hline Per capita GDP (Yuan) & $<25000$ & $25000 \sim 45000$ & $>45000$ \\
\hline Economic density $\left(10^{4}\right.$ Yuan $\left./ \mathrm{km}^{2}\right)$ & $<1800$ & $1800 \sim 4200$ & $>4200$ \\
\hline The proportion of the secondary and the tertiary industry (\%) & $<85$ & $85 \sim 95$ & $>95$ \\
\hline GDP density of the secondary and the tertiary industry $\left(10^{4}\right.$ Yuan $\left./ \mathrm{km}^{2}\right)$ & $<1800$ & $1800 \sim 4000$ & $>4000$ \\
\hline Per capita industrial output (Yuan) & $<9000$ & $9000 \sim 17000$ & $>17000$ \\
\hline Per capita disposable income of urban residents (Yuan) & $<11000$ & $11000 \sim 17000$ & $>21000$ \\
\hline Per capita living area $\left(\mathrm{m}^{2}\right)$ & $<20$ & $20 \sim 28$ & $>28$ \\
\hline Urban density (human $/ \mathrm{km}^{2}$ ) & $<507$ & $570 \sim 690$ & $>690$ \\
\hline Per capita public green area $\left(\mathrm{m}^{2}\right)$ & $<8$ & $8 \sim 16$ & $>16$ \\
\hline Per capita road pavement area $\left(\mathrm{m}^{2}\right)$ & $<9$ & $9 \sim 13$ & $>13$ \\
\hline Number of buses per ten thousand people (pcs) & $<8$ & $8 \sim 12$ & $>12$ \\
\hline
\end{tabular}

TABle 6: Measure index grade values of water resource conflict risk levels in Beijing City, Tianjin City, and Hebei Province in Haihe river basin of China.

\begin{tabular}{|c|c|c|c|}
\hline Level grade & Low & Middle & High \\
\hline Volume of water $\left(10^{8} \mathrm{~m}^{3}\right)$ & $<125$ & $125 \sim 135$ & $>135$ \\
\hline Water consumption of GDP per 10 thousands Yuan (tons) & $<60$ & $60 \sim 160$ & $>160$ \\
\hline Annual per capita domestic water consumption (tons) & $<180$ & $180 \sim 220$ & $>220$ \\
\hline Sewage treatment rate $(\%)$ & $<50$ & $50 \sim 88$ & $>88$ \\
\hline Industrial wastewater discharge standards rate (\%) & $<94$ & $94 \sim 98$ & $>98$ \\
\hline Environmental water $\left(10^{8} \mathrm{~m}^{3}\right)$ & $<1$ & $1 \sim 2.4$ & $>2.4$ \\
\hline
\end{tabular}

$$
\begin{aligned}
& \widetilde{R}_{2} \\
& =\left[\begin{array}{llllll}
0.0000 & 0.0000 & 0.0696 & 0.0826 & 0.0315 & 0.3557 \\
0.7051 & 0.8632 & 0.9304 & 0.9174 & 0.9685 & 0.6443 \\
0.2949 & 0.1368 & 0.0000 & 0.0000 & 0.0000 & 0.0000
\end{array}\right], \\
& \widetilde{R}_{3} \\
& =\left[\begin{array}{lllllll}
0.0000 & 0.0625 & 0.1227 & 0.0177 & 0.0000 & 0.1170 \\
0.7743 & 0.9375 & 0.8773 & 0.9823 & 0.7670 & 0.8830 \\
0.2257 & 0.0000 & 0.0000 & 0.0000 & 0.2330 & 0.0000
\end{array}\right], \\
& \widetilde{R}_{4} \\
& =\left[\begin{array}{lllllll}
0.2211 & 0.2475 & 0.2323 & 0.0000 & 0.0000 & 0.0000 \\
0.7789 & 0.7525 & 0.7677 & 0.7821 & 0.7860 & 0.8452 \\
0.0000 & 0.0000 & 0.0000 & 0.2180 & 0.2140 & 0.1548
\end{array}\right], \\
& \widetilde{R}_{5} \\
& =\left[\begin{array}{llllll}
0.2735 & 0.3125 & 0.2802 & 0.0000 & 0.0000 & 0.0000 \\
0.7265 & 0.6875 & 0.7199 & 0.6381 & 0.0000 & 0.8452 \\
0.0000 & 0.0000 & 0.0000 & 0.3619 & 0.3822 & 0.1548
\end{array}\right],
\end{aligned}
$$

$\widetilde{R}_{6}$

$$
=\left[\begin{array}{llllll}
0.2936 & 0.4376 & 0.3474 & 0.0000 & 0.0000 & 0.0000 \\
0.7064 & 0.5624 & 0.6526 & 0.0000 & 0.0000 & 0.7218 \\
0.0000 & 0.0000 & 0.0000 & 0.4941 & 0.3541 & 0.2783
\end{array}\right] .
$$

Calculate nonlinear fuzzy comprehensive level: water resource conflict risk levels in Beijing City, Tianjin City, and Hebei Province from 2005 to 2010 are determined as follows with combination of formula (2):

$$
\begin{aligned}
& \widetilde{B}_{1}=\widetilde{W} \cdot \widetilde{R}_{1}=(0.2442,0.6204,0.1353), \\
& \widetilde{B}_{2}=\widetilde{W} \cdot \widetilde{R}_{2}=(0.1605,0.7793,0.0601), \\
& \widetilde{B}_{3}=\widetilde{W} \cdot \widetilde{R}_{3}=(0.0793,0.9200,0.0007), \\
& \widetilde{B}_{4}=\widetilde{W} \cdot \widetilde{R}_{4}=(0.1095,0.7955,0.0950), \\
& \widetilde{B}_{5}=\widetilde{W} \cdot \widetilde{R}_{5}=(0.1382,0.7464,0.1150), \\
& \widetilde{B}_{6}=\widetilde{W} \cdot \widetilde{R}_{6}=(0.1930,0.5518,0.1849) .
\end{aligned}
$$

Calculate water resource conflict risk level: water resource conflict risk levels in Beijing City, Tianjin City, and Hebei 
Province from 2005 to 2010 can be obtained as follows according to maximum membership principle:

$$
\begin{aligned}
g & =(g(1), g(2), \ldots, g(6)) \\
& =(0.6204,0.7793,0.92,0.7955,0.7464,0.5518) .
\end{aligned}
$$

\subsection{Coupling and Coordination Analysis on Urbanization Development Speed and Water Resource Conflict Risk Pressure}

Step 1 (determine urbanization development speed). Urbanization development speeds in Beijing City, Tianjin City, and Hebei Province from 2005 to 2009 are obtained as follows by calculating formula (3): $\widetilde{f}=(\widetilde{f}(1), \widetilde{f}(2), \ldots, \widetilde{f}(5))=$ $(0.1299,0.1134,0.0120,0.0438,0.2139)$. From the calculation results of urbanization development speeds in Beijing City, Tianjin City, and Hebei Province from 2005 to 2009, it can be seen that sequential variation of urbanization development speed fluctuated obviously and rising trend is shown as a whole.

Step 2 (determine water resource conflict risk pressure). Water resource conflict risk pressures in Beijing City, Tianjin City, and Hebei Province from 2005 to 2009 are obtained as follows by calculating formula (4): $\widetilde{g}=(\widetilde{g}(1)$, $\widetilde{g}(2), \ldots, \widetilde{g}(5))=(0.2561,0.1805,0.1353,0.0617,0.2607)$. From the calculation results of water resource conflict risk pressures in Beijing City, Tianjin City, and Hebei Province from 2005 to 2009, it can be seen that sequential variation of water resource conflict risk pressure fluctuated obviously and rising trend is also shown as a whole.

Step 3 (coupling coordination analysis). Coupling coordination degree between urbanization development speeds and water resource conflict risk pressures in Beijing City, Tianjin City and Hebei Province from 2005 to 2009 is obtained as follows with calculation $G=[G(1), \ldots, G(5)]=$ $(0.1824,0.1431,0.0402,0.0520,0.2361)$; obtained comprehensive compatibility index between urbanization development speeds and water resource conflict risk pressures in Beijing City, Tianjin City, and Hebei Province from 2005 to 2009 is $T=[T(1), \ldots, T(5)]=$ $(0.7977,0.8983,0.0891,0.9432,0.9806)$; coupling coordination development degree between urbanization development speeds and water resource conflict risk pressures in Beijing City, Tianjin City, and Hebei Province from 2005 to 2009 can be obtained according to formula (5): $C=[C(1), \ldots, C(5)]=$ $(0.5260,0.5047,0.1530,0.3660,0.6141)$.

According to coupling coordination development degree between urbanization development speeds and water resource conflict risk pressures in Beijing City, Tianjin City, and Hebei Province from 2005 to 2009, we can obtain the line figure of coupling coordination development degree between urbanization development speeds and water resource conflict risk pressures in Beijing City, Tianjin City, and Hebei Province from 2005 to 2009 as shown in Figure 2.

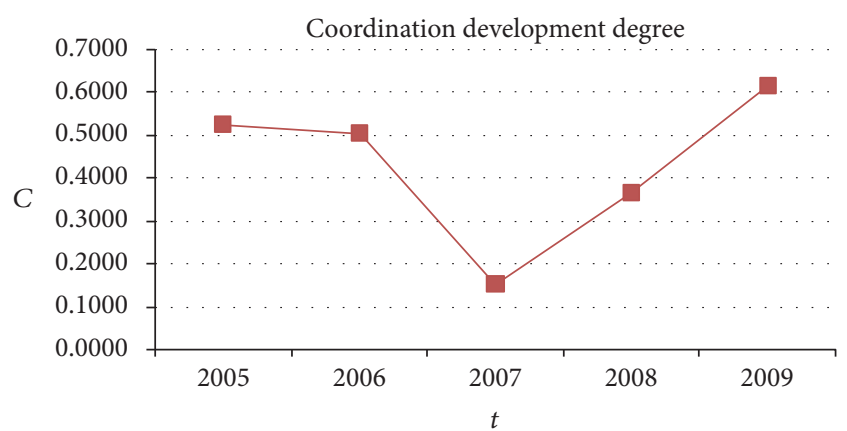

FIGURE 2: Line figure of coupling coordination development degree between urbanization development speeds and water resource conflict risk pressure from 2005 to 2009.

\section{Conclusion and Analysis}

6.1. Coupling Relationship between Urbanization Development Speed and Water Resource Conflict Risk Pressure. As can be seen from Figure 2, the coupling coordinated development degree in terms of urbanization development speed and water resource conflict risk pressure in Beijing City, Tianjin City, and Hebei Province tends to fluctuant rising in 2005 to 2009, but there is difference within each city and the change is very complex. On the basis of judgment standards of coupling coordination rank, in accordance with Figure 2 and according to the practical situation regarding urbanization development speed and water resource conflict risk pressure in Beijing City, Tianjin City, and Hebei Province, the rank of coupling coordination for Haihe river basin of China (Beijing City, Tianjin City, and Hebei Province) in 2005 to 2009 can be concluded.

In 2005, 2006, and 2009, the degree of coupling coordinated development regarding urbanization development speed and water resource conflict risk pressure varies between 0.5047-0.6141; the coupling coordinated type of urbanization development speed and water resource conflict risk pressure belongs to coordinated development type and the degree of coupling coordination is moderately coordinated development coupling, which indicates the urbanization and water resource develop harmoniously and orderly. In fact, in 2005, 2006, and 2009, there is no water resource conflict in Haihe river basin of China (Beijing City, Tianjin City, and Hebei Province).

In 2007, the degree of coupling coordinated development regarding urbanization development speed and water resource conflict risk pressure is 0.1530 ; the coupling coordinated type of urbanization development speed and water resource conflict risk pressure belongs to uncoordinated development type and the degree of coupling coordination is slightly coordinated development coupling. In fact, in 2007, 12 water resource conflict events occur in Beijing City, Tianjin City, and Hebei Province, such as water diversion conflict between Beijing City and Hebei Province Juma River, water event conflict between Beijing City and Hebei Province right bank of Yongding River (Golden Gate to Hanying section), 
and conflict between Tianjin City and Jinhai Lake; all conflicts are serious water resource conflict events.

In 2008, the degree of coupling coordinated development regarding urbanization development speed and water resource conflict risk pressure is 0.3660 ; the coupling coordinated type of urbanization development speed and water resource conflict risk pressure belongs to transition type and the degree of coupling coordination is slightly coordinated development coupling. In fact, in 2008, only 2 water resource conflict events occurred, in Beijing City, Tianjin City, and Hebei Province.

The example analysis of Haihe river basin of China (Beijing City, Tianjin City, and Hebei Province) in 2005 to 2010 indicates the urbanization development may indeed cause water resource conflict, especially the excessively fast urbanization development; it may cause serious water resource conflicts.

6.2. Determination of Water Resource Threshold. According to the rank of coupling coordination regarding urbanization development speed and water resource conflict risk pressure in 2007 and 2008, the threshold which causes water resource conflict in Haihe river basin of China (Beijing City, Tianjin City, and Hebei Province) can be obtained through analysis. As the year of 2007 belongs to slightly uncoordinated development coupling year, but the year of 2008 belongs to slightly coordinated development coupling year, the water utilization index in these two years can be used as reference to judge whether the urbanization development speed will cause increasing of water resource conflict risk pressure. The threshold which causes water resource conflict in Beijing City, Tianjin City, and Hebei Province can be obtained through analyzing the data in Table 4 . The two indexes in water yield conflict are as follows: the threshold for GDP water consumption per ten thousand Yuan is [85.25, 103.75] ton and for annual domestic consumption per capita is [196.06, 202.64] ton. These two indexes are represented by interval number; if the urbanization develops at a too fast speed and GDP water consumption per ten thousand Yuan for Beijing City, Tianjin City, and Hebei Province is in [85.25, 103.75] ton or the annual domestic consumption per capita is in $[196.06,202.64]$ ton, it will enter into intense situation and water resource conflict may occur, which must be paid much attention by water resource management department.

\section{Competing Interests}

The authors declare that there is no conflict of interests regarding the publication of this paper.

\section{References}

[1] M. Majumder, Impact of Urbanization on Water Shortage in Face of Climatic Aberrations, Springer Briefs in Water Science and Technology, 2015.

[2] X. Gao, T. F. Yu, and H. B. Cheng, “Temporal-spatial variation of systemic coupling between water resources and environment and urbanization in northwest China: a case study of Gansu section of Western Longhai-Lanxin Economic Zone," Arid Land Geography, vol. 33, no. 6, pp. 1010-1018, 2010.

[3] Y. B. Liu, R. D. Li, and X. F. Song, "Analysis of coupling degree of urbanization and ecological environment in China," Journal of Natural Resources, vol. 20, no. 1, pp. 105-112, 2005.

[4] G. D. Jenerette and L. Larsen, "A global perspective on changing sustainable urban water supplies," Global \& Planetary Change, vol. 50, no. 3-4, pp. 202-211, 2006.

[5] C. B. Liao, "Quantitative judgment and classification system of coordinated development of environment and economy-a case study of the city group in the Pearl River Delta," Tropical Geography, vol. 24, no. 2, pp. 171-177, 1999.

[6] Y. B. Liu, R. D. Li, and S. Z. Zhang, "Study on the coordinative criteria and coordination degree model between regional urbanization and eco-environment," China Soft Science, vol. 34, no. 5, pp. 140-148, 2005.

[7] X. M. Wang, Y. B. Wang, and L. X. Wang, "Evaluation research on urbanization and ecological environment coordination development of Tianshui City," Resource Development \& Market, vol. 30, no. 4, pp. 442-447, 2014.

[8] L. B. Ma, S. W. Niu, and Y. X. Li, "Quantitative analysis of coupling between urbanization and ecological environment in Gansu Province," Urban Studies, vol. 17, no. 5, pp. 52-58, 2010.

[9] C. Bao and C.-L. Fang, "Water resources constraint force on urbanization in water deficient regions: a case study of the Hexi Corridor, arid area of NW China," Ecological Economics, vol. 62, no. 3-4, pp. 508-517, 2007.

[10] S. G. Furey and B. C. Lutyens, "Developing an integrated water management strategy to overcome conflicts between urban growth, water infrastructure and environmental quality: a case study from Ashford, Kent," Water and Environment Journal, vol. 22, no. 1, pp. 42-53, 2008.

[11] H. S. Fan and L. H. Tao, The Process of Urbanization in China, People's Publishing House, Beijing, China, 2009.

[12] N. R. He and Y. Wu, Theoretical Research on Chinese Contemporary Urbanization, Shanghai People's Publishing House, Shanghai, China, 2007.

[13] Q. Q. Bai, L. C. Wang, and X. M. Yang, "Development model of urbanization under water resources carrying capacity-Take Heihe River Basin Zhangye City as a case," Journal of Arid Land Resources and Environment, vol. 19, no. 4, pp. 75-78, 2009.

[14] Y. B. Liu, Y. Liu, and G. M. Hu, "Measurement and analysis on appropriate level of urbanization under constraint of resources and environment in Jiangsu," East China Economic Management, vol. 29, no. 10, pp. 14-17, 2011.

[15] H. K. Wei, "Regional carrying capacity, urbanization and urban development policy," Academics, vol. 11, no. 6, pp. 77-80, 1989.

[16] Z.-Y. Yang, J.-B. Qu, and C.-K. Huang, "Bridge safety evaluation based on fuzzy synthetic evaluation method and analytic hierarchy process," Journal of Tianjin University Science and Technology, vol. 38, no. 12, pp. 1063-1067, 2005.

[17] X.-H. Zhang and Y.-J. Feng, "A nonlinear fuzzy comprehensive assessment model," System Engineering Theory and Practice, vol. 36, no. 10, pp. 54-59, 2005.

[18] G. Bee-Hua, "Evaluating the performance of combining neural networks and genetic algorithms to forecast construction demand: the case of the Singapore residential sector," Construction Management \& Economics, vol. 18, no. 2, pp. 209-217, 2000.

[19] B.-G. Hu, G. K. I. Mann, and R. G. Gosine, "Control curve design for nonlinear (or fuzzy) proportional actions using spline-based functions," Automatica, vol. 34, no. 9, pp. 11251133, 1998. 
[20] Z. F. Yang and Y. Zeng, "Mathematical model for water conflict and coordination in Tran boundary regions," Acta Scientiae Circumstantiae, vol. 24, no. 1, pp. 71-76, 2004.

[21] Z. C. Yao and Q. An, "Analysis on the conflict and coordination of eco-economic system of water resources," South-to-North Water Transfers and Water Science \& Technology, vol. 9, no. 4, pp. 77-80, 2011.

[22] L. J. Ren, C. C. Yuan, and Z. J. Cui, "Study on the prediction of urban water resources requirement of Shandong Province," Journal of Shandong University (Natural Science), vol. 32, no. 9, pp. 27-41, 2008. 


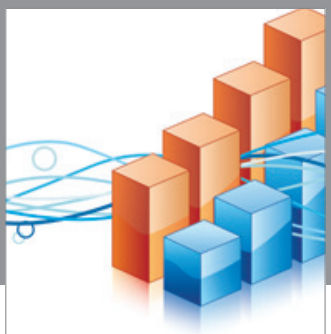

Advances in

Operations Research

vatem alat4

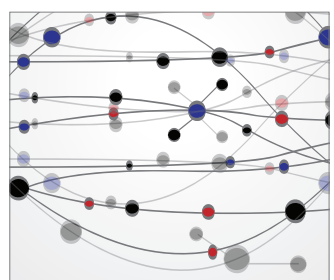

\section{The Scientific} World Journal
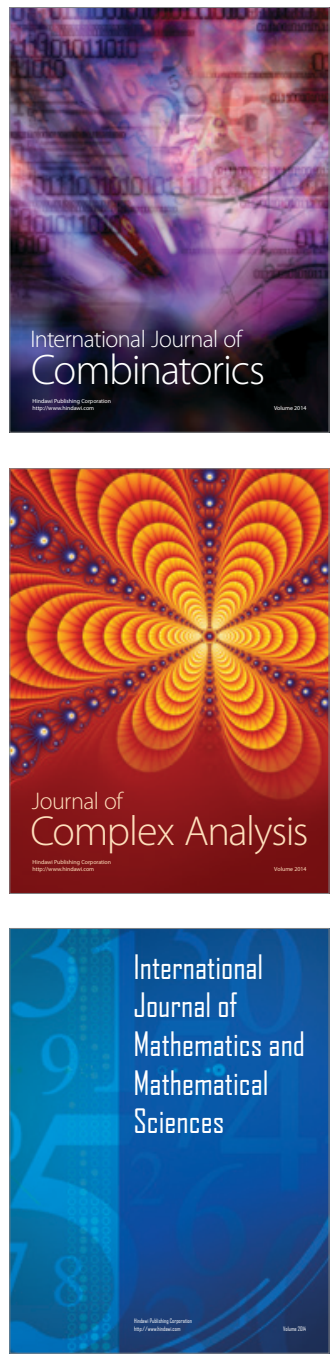
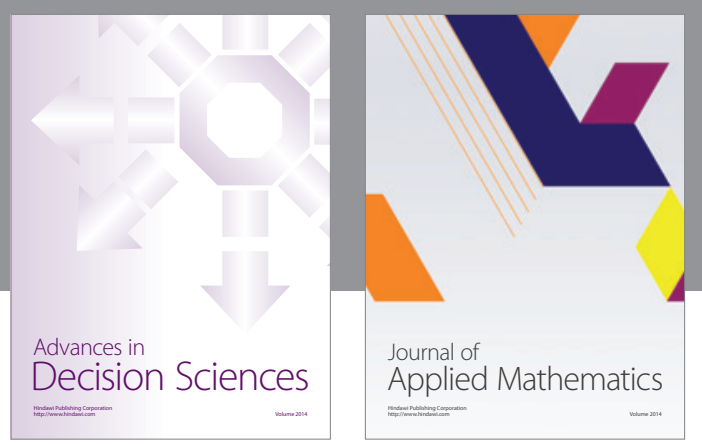

Algebra

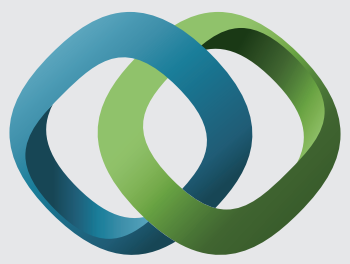

\section{Hindawi}

Submit your manuscripts at

https://www.hindawi.com
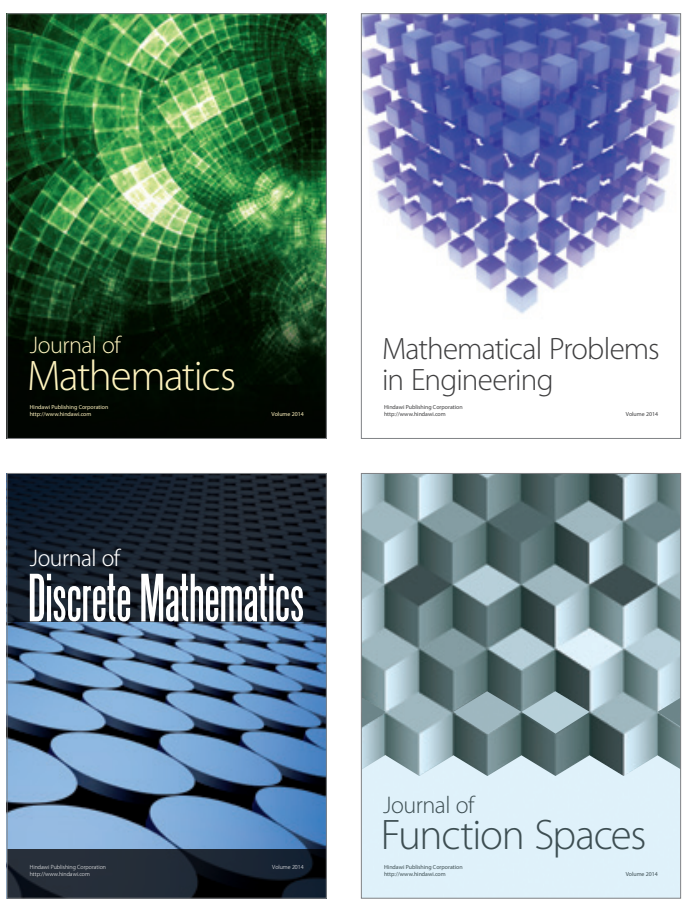

Mathematical Problems in Engineering
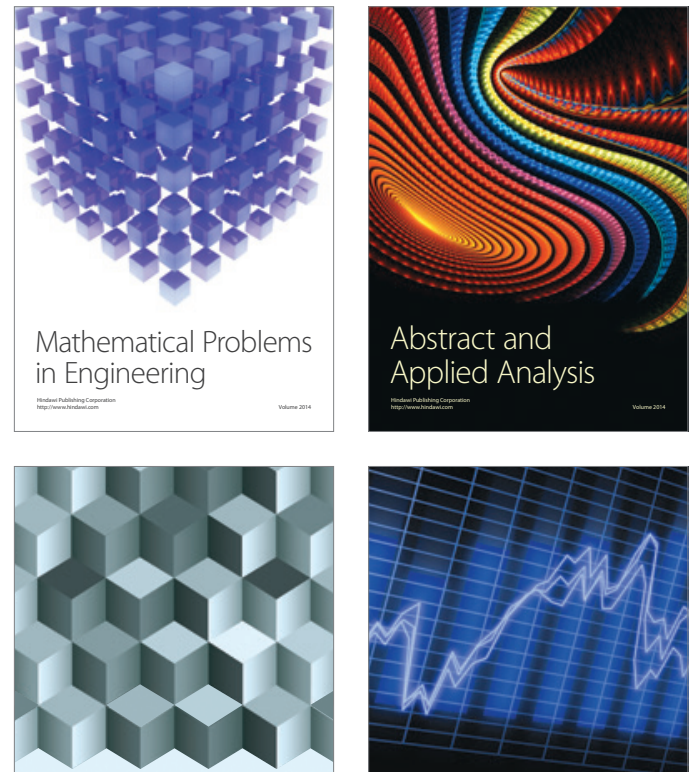

Journal of

Function Spaces

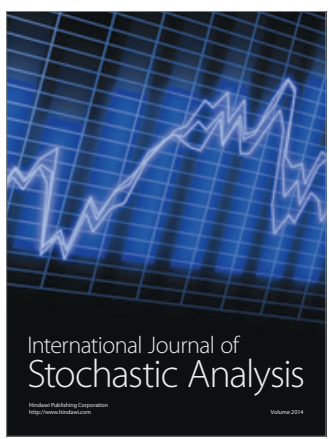

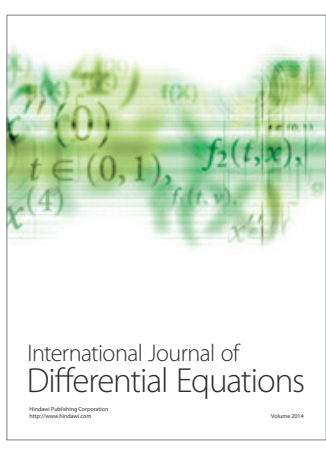
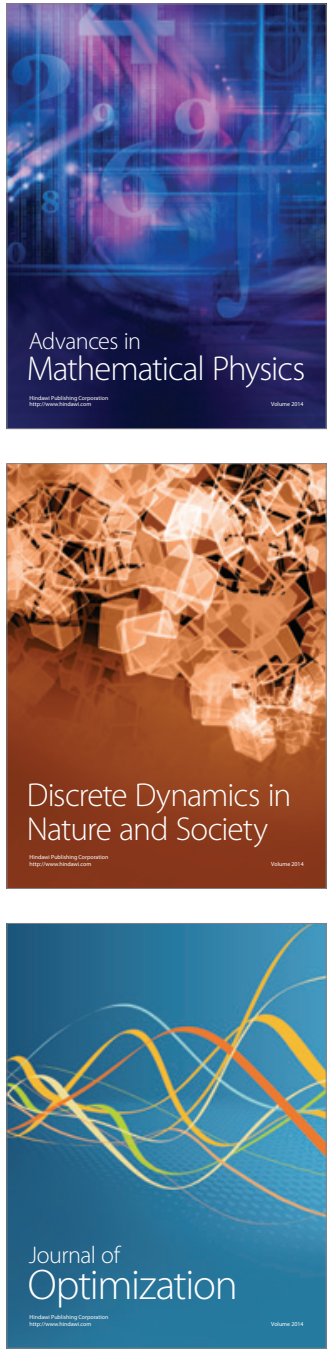